\title{
ENTREVISTA A CARMEN MOGUEL GONZÁLEZ INTERVIEW TO CARMEN MOGUEL GONZÁLEZ
}

\author{
Esther Gil de Reboleño \\ Universidad de Cádiz \\ https://orcid.org/0000-0002-1115-3913 \\ egr173@gmail.com
}

\begin{tabular}{|lllll}
\hline Cómo citar este artículo: Moguel, C. (2020). Entrevista a Carmen Moguel González. & Hachetetepé. \\
Revista cientifica en Educación y lomunicación, (20), & $117-120$. doi: \\
http://doi.org/10.25267/Hachetetepe.2020.i20.17 & & & & \\
\hline
\end{tabular}

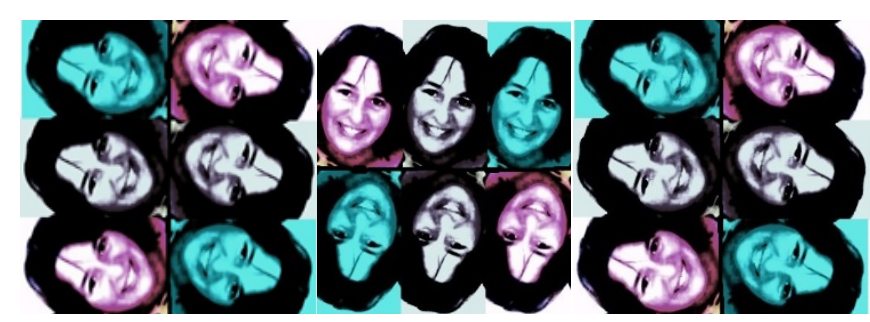

Carmen Moguel González

Maestra, psicopedagoga y doctora en educación

Carmen Moguel González se desenvuelve entre el pragmatismo de una persona realista y entre el romanticismo de la que añora un mundo mejor. Por eso, es maestra y psicopedagoga. Con todo lo que supone (de implicación y responsabilidad) fue, es y será voluntaria social. Cree en el posible cambio a mejor de las personas, considera que al igual que hay una segunda oportunidad debería haber una tercera o cuarta... Habla de forma serena, mira a los ojos, escucha con atención, sonríe y se considera una feminista del siglo XXI; una mujer de hoy en día. Es una luchadora que se abandera de las causas injustas, que sueña con los ojos bien abiertos y que no tiene pudor en llamar a las cosas por su nombre.

\section{1. ¿Cómo describirías la palabra carta?}

Como un medio de comunicación, tristemente, en desuso.

\section{2. ¿Qué sentido tienen las cartas en la actualidad?}

Creo que bastante poco, por lo menos como las concebimos nostálgicamente. Aunque pienso que las seguimos escribiendo pero en los nuevos soportes digitales y con unos formatos menos convencionales de los que nos enseñaron cuando era básicamente la única forma de comunicación interpersonal.

3. ¿Qué quedan de las cartas del ayer? Aquellas que se escribían con puño y letra, que se coloreaban, que se decoraban de manera especial...

Sinceramente, poco, por los menos con el protocolo formal de colocarle su sello, para lo que debíamos dirigirnos al estanco del barrio, de depósito en el buzón más cercano o en 
la ventanilla de correos y de la alegría que nos envolvía sabiendo que algo nuestro llegaba a una persona querida y que en breve recibiríamos su respuesta.

\section{Y, si habláramos de las cartas en la prisión de mujeres, ¿qué papel juegan en la vida de las reclusas?}

Vaya, pues éstas sí que siguen teniendo esos tintes del ayer. En un establecimiento penitenciario todo es diferente, es como un micromundo que tiene sus propias formas para comunicarse entre ellas y ellos. Las cartas en las cárceles y sobre todo en los módulos de mujeres donde he tenido más contacto y experiencias, puedo afirmar que son muy importantes para las reclusas. En mi modesta opinión, son en la mayoría de los casos un alivio emocional, en ellas expresan sus sentimientos sin tapujos, sus quehaceres y su día a día allí dentro, sus quejas, sus preocupaciones,... incluso en ocasiones son utilizadas para castigarlas, reteniéndoselas hasta que consideran oportuno.

En la cárcel las cartas son una ventana hacia el exterior.

5. En su tesis doctoral, en la cual trabajó sobre mujer, prisión y educación, ¿qué papel desempeñaron las cartas?

Las cartas fueron una herramienta insustituible para poder entender muchos de los aspectos que fueron estudiados. Completaban perfectamente la información obtenida en las entrevistas y en las observaciones realizadas. En su soledad expresaban a través de las cartas ese mundo interior y aspectos que en un encuentro o en una entrevista formal no eran capaces. Me llamaba sobremanera la atención el hecho de contarlo todo, desde una ruptura con su pareja, a un conflicto en el módulo,...

\section{En este sentido, ¿qué fue lo que más le llamó la atención?}

El carteo que he mantenido con muchas internas durante años, aunque se marcharan a otras prisiones siempre llegaba a tiempo la felicitación navideña, la gran noticia de un primer permiso, la libertad, la maternidad de muchas de ellas, el comienzo de un nuevo trabajo,... y esos mensajes de cariño y preocupación por mi situación. Siempre atentas a mis circunstancias.

\section{Como educadora, ¿qué opinión le merecería saber que alguien ha castigado a una} reclusa sin poder escribir una carta?

Bueno, sin escribirla no sé si se daba el caso, porque la solidaridad entre ellas era tremenda y siempre buscaban las maneras para pasarle folios, cuartillas, tarjetas,... a las compañeras. Lo que sí presencié en ocasiones y como ya dije antes fue la utilización por parte del personal penitenciario de las cartas como forma de castigo, se las retenían y las dejaban en la garita a la vista de ellas para que supieran que estaba ahí pero que no se la darían hasta que lo viesen oportuno. Esto les provocaba una desazón impresionante porque muchas veces esperaban noticias importantes de su familia.

\section{Como educadora en prisión de mujeres, ¿cuál fue la carta que más le ha llamado la atención?}

Sin duda la que recibí de un grupo de internas después de mi maternidad. Por supuesto la guardo, como todas las que he recibido, como un gran tesoro. Esa carta me emocionó tanto que ahora que recuerdo ese momento se me pone la piel de gallina. Fue una carta llena de cariño, con unos mensajes repletos de empatía y de consejos para afrontar mi 
recién estrenada maternidad. Llena de dibujos, de posdatas y recuerdos de muchas otras internas. Con el papel y el sobre aprovechados al milímetro. Con besos marcados con pintalabios y pequeñas manualidades de hilo hechas para mi hija Amanda. Todavía me pregunto cómo el centro pudo enviarla sin que fuera devuelta por la cantidad de detalles que habían metido...

9. ¿Has sido testigo de que alguna interna haya ayudado, a otra mujer privada de libertad, a escribir una carta?

Sí, claro, y yo misma. Al comienzo de nuestra labor en prisión desde el Colectivo CEPACádiz, una de las actividades estrella era la alfabetización de las internas. Muchas de ellas eran analfabetas y jamás habían ido al colegio. De repente, se encontraban en un medio en el que las comunicaciones de ellas hacia el centro tenían que ser escritas y a la inversa, la información que les llegaba también era escrita. Además, como ya he dicho antes la comunicación con sus familiares y amigos eran por carta. Así, que la ayuda de las reclusas que sabían leer y escribir y las que no eran constantes. También fui testigo de voluntarios y voluntarias de otras ONGs que les ayudaban a escribir y leer sus cartas y de funcionarios/as que también lo hacían.

A día de hoy las llamadas se han extendido más en los centros penitenciarios, pero hace años conseguir que autorizaran las comunicaciones telefónicas y tener dinero para afrontarlas era difícil para una gran mayoría de internas.

10. Como educadora, ¿has organizado algún taller de escritura de cartas? Y ¿lo harías?

Sí, eran bastante demandados. También organizábamos talleres de cartas ficticias por ejemplo, qué le escribirías a tu madre, al director de la cárcel, a una mujer maltratada, a un amigo... dentro de talleres específicos por el día de la mujer, de la madre, etc.

11. En prisión, ¿has conocido algún caso de que entre las internas se hayan robado una carta?

Sí, ya digo que tanto funcionarias como internas utilizaban las cartas para castigar o vengarse de otras reclusas. Aunque he de decir que no era un hecho muy repetido afortunadamente.

12. En prisión, ¿se iluminan las caras cuando llegan las cartas?

A partes iguales se iluminan y se ensombrecen, como fuera de la cárcel. Unas veces se reciben buenas noticias y otras veces malas, y éstas dentro y sin capacidad de reacción son terriblemente jodidas.

\section{Y ihas sido testigo de alguna mala noticia?}

Desgraciadamente de muchas. La que no olvidaré nunca fue la carta que le dieron a una de las internas en la que la prisión le comunicaba del fallecimiento de su hijo que estaba en la misma prisión pero en otro módulo. Todavía se me hace un nudo en la garganta al recordarlo.

14. Si tuvieses que escribir una carta al presidente del gobierno, contándole qué sentido tiene la privación de libertad, ¿qué le dirías? 
Resumidamente y para que pudiera entenderlo con facilidad y dispusiera las medidas necesarias, le escribiría: "señor presidente del gobierno, privación de libertad sin medios reales para la reinserción, no sirve para nada. Disponga de recursos tanto humanos como materiales para que las cárceles sirvan para reinsertar a las personas más vulnerables...”. Ufff le diría tantas cosas que no son políticamente correctas que prefiero dejarlo aquí.

15. Si tuvieses que escribir una carta a mujer víctima de malos tratos, ¿cómo la empezarías? Y ¿por qué?

Con una pregunta: ¿te puedo ayudar? Y una afirmación: estoy aquí para acompañarte. Porque muchas veces nos olvidamos de que son ellas las que tienen que sentir la capacidad de pedir ayuda y decirnos qué necesitan para superar una situación tan dramática como la de los malos tratos. Desde el primer momento, creo que tienen que sentir la capacidad y la valía que tienen para volver a tomar las riendas de su vida sin miedos.

16. Si tuvieses que escribir una carta a una joven en situación vulnerable, ¿qué última frase le pondrías? Y ¿por qué?

Lucha, sé tú misma y busca ayuda para salir de esa situación. Porque ninguna persona debe rendirse ante la adversidad y porque confío en la naturaleza humana para ayudar a los demás, aunque a veces parezca que esté por extinguirse este rasgo de empatía y solidaridad que debería desbordarnos.

17. Si tuvieses que escribir una carta a una educadora social, ¿cómo te despedirías de ella?

Disfruta de tu trabajo, porque lo que aprenderás con los colectivos más desfavorecidos no viene en ningún manual y te hará más feliz y mucho mejor persona.

18. Si tuvieses que escribirte una carta a ti misma, ¿qué es lo que no olvidarías en su redacción?

No te rindas, todo lo que quieres está aquí y ahora. Disfruta cada instante con alegría.

19. Por último, ¿qué poder tiene una carta?

Todo el que queramos darle al escribirla o al recibirla, pero quizás, el mayor poder que le otorgo a la carta escrita es que cada una es irrepetible y describe el momento justo en el que se escribe o en el que se recibe. 